\section{ORIGINAL RESEARCH}

\section{R.M. Ahmed}

M. Wilkinson

G.D. Parker

M.J. Thurtell

J. Macdonald

P.J. McCluskey

R. Allan

V. Dunne

M. Hanlon

B.K. Owler

G.M. Halmagyi

\title{
Transverse Sinus Stenting for Idiopathic Intracranial Hypertension: A Review of 52 Patients and of Model Predictions
}

\begin{abstract}
BACKGROUND AND PURPOSE: Transverse sinus stenosis is common in patients with IIH. While the role of transverse sinus stenosis in IIH pathogenesis remains controversial, modeling studies suggest that stent placement within a transverse sinus stenosis with a significant pressure gradient should decrease cerebral venous pressure, improve CSF resorption in the venous system, and thereby reduce intracranial (CSF) pressure, improving the symptoms of $\mathrm{IH}$ and reducing papilledema. We aimed to determine if $\mathrm{IH}$ could be reliably treated by stent placement in transverse sinus stenosis.
\end{abstract}

MATERIALS AND METHODS: We reviewed the clinical, venographic, and intracranial pressure data before and after stent placement in transverse sinus stenosis in 52 of our own patients with $\mathrm{IIH}$ unresponsive to maximum acceptable medical treatment, treated since 2001 and followed between 2 months and 9 years.

RESULTS: Before stent placement, the mean superior sagittal sinus pressure was $34 \mathrm{~mm} \mathrm{Hg}$ (462 mm $\mathrm{H}_{2} \mathrm{O}$ ) with a mean transverse sinus stenosis gradient of $20 \mathrm{~mm} \mathrm{Hg}$. The mean lumbar CSF pressure

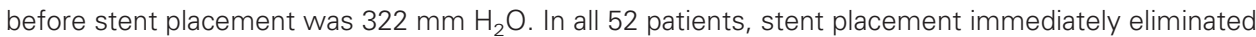
the TSS pressure gradient, rapidly improved IIH symptoms, and abolished papilledema. In 6 patients, symptom relapse (headache) was associated with increased venous pressure and recurrent stenosis adjacent to the previous stent. In these cases, placement of another stent again removed the transverse sinus stenosis pressure gradient and improved symptoms. Of the 52 patients, 49 have been cured of all IIH symptoms.

CONCLUSIONS: These findings indicate a role for transverse sinus stent placement in the management of selected patients with $\mathrm{IIH}$.

ABBREVIATIONS: ATECO = autotriggered elliptic centric-ordered; $\| \mathrm{H}=$ idiopathic intracranial hypertension; $L P=$ lumbar puncture; $M R V=M R$ venography; $\mathrm{pCO} 2=$ partial pressure of carbon dioxide; TSS $=$ transverse sinus stenosis

IH, a syndrome of intracranial hypertension without mass lesion, hydrocephalus, or cerebral edema, was first described as "meningitis serosa" more than 100 years ago (for a review see Owler et al $2005^{1}$ ). In the past decade, it has become clear that there may be multiple interacting potential causes, ${ }^{2-4}$ including transverse sinus stenosis. ${ }^{5}$

CTV and MRV studies show that many patients with IIH have stenoses either of both transverse sinuses or of the dominant one. ${ }^{6,7}$ Previously, with time-of-flight MRV, these appearances were often interpreted as flow-related artifacts, ${ }^{8}$ but with improved MRV techniques, particularly the ATECO technique, ${ }^{9}$ venous abnormalities have been demonstrated with confidence. Direct retrograde cerebral venography and manometry show that transverse sinus stenosis can be real and significant, with high superior sagittal sinus pressure above and a pressure gradient across the stenosis. ${ }^{7}$ However, it is not yet clear whether the transverse sinus stenosis is the cause or a consequence of the intracranial hypertension or whether it is, in fact, both.

\section{Received September 28, 2010; accepted after revision January 5, 2011.}

From the Departments of Neurology (R.M.A., M.J.T., G.M.H.), Radiology (M.W., G.D.P., J.M.), Ophthalmology (P.J.M.), and Neurosurgery (R.A., V.D., M.H.), Royal Prince Alfred Hospital, Sydney, Australia; and Department of Neurosurgery (B.K.O.), Westmead Hospital, Sydney, Australia.

Please address correspondence to G.M. Halmagyi, MD, Department of Neurology, Royal Prince Alfred Hospital, Missenden Rd, Camperdown, Sydney, NSW, Australia 2050; e-mail: gmh@icn.usyd.edu.au

Indicates article with supplemental on-line appendix at www.ajnr.org http://dx.doi.org/10.3174/ajnr.A2575
Transverse sinus stenoses can be seen in 2 morphologic forms: an extrinsic smooth gradually narrowing tapered stenosis ${ }^{7}$ and intrinsic discrete obstructions, presumably due to arachnoid granulations or fibrous septae. ${ }^{10,11}$ While intrinsic transverse sinus stenosis might cause IIH by completely occluding the transverse sinus, the extrinsic compression, which resolves with CSF drainage, ${ }^{12-16}$ might be secondary to the intracranial hypertension.

Transverse sinus stent placement for IIH has been reported in small case series. ${ }^{17-24}$ In the past 9 years, we have stented 1 transverse sinus in 52 patients with $\mathrm{IIH}$ with transverse sinus stenosis who either failed medical treatment or had fulminant visual loss. We reviewed the data; on the basis of a mathematic model $^{25}$ that incorporates a collapsible transverse sinus as a Starling-like resistor (one in which the resistance is a linear function of pressure external to the resistor lumen), we attempted to reconcile opposing views of transverse sinus stenosis as a cause and a consequence of intracranial hypertension. We believe that stent placement in a collapsible transverse sinus removes the Starling-like resistor, interrupting a positive feedback cycle, lowering intracranial pressure, and curing the symptoms of IIH.

\section{Materials and Methods}

\section{Patients}

In 46 patients, the diagnosis of IIH was made on the basis of the updated Modified Dandy criteria ${ }^{26}$ : papilledema without mass lesion 
or ventriculomegaly but with elevated CSF pressure measured at the spinal level by LP or inferred at the cerebral level by sagittal sinus manometry or by both. Six patients had headache without papilledema ${ }^{27}$ but had high CSF and venous pressures and the other clinical features of IIH. Direct retrograde cerebral venography and manometry were performed only if the MRV suggested stenosis in 1 dominant or of both transverse sinuses. Thirty-seven patients had their CSF pressure measured at the spinal level by LP, while all 52 patients underwent sagittal sinus manometry. All 52 patients had transverse sinus stenosis, unremitting symptoms resistant to conventional medical therapies, and a pressure gradient in a dominant transverse sinus or in both transverse sinuses.

Ethics approval was not required by the authors' institutions because transverse sinus stent placement was offered as a medical treatment and all patients gave full informed consent.

Age and Sex. The mean age of the patients was 34 years (range, 10-64 years); 47 were female and 5 were male.

Body Mass Index and Duration of Symptoms. Forty-seven of the 52 patients included in the study had a body mass index of $>30$. The mean duration of symptoms before stent placement was 23 months (range, 1 month to 12 years)

Clinical Assessment. Pre- and post-stent placement, we reviewed and classified patients' symptoms - that is, headache (mild, moderate, and severe), visual obscurations (mild, moderate, and severe depending on degree of visual loss), pulsatile tinnitus (mild, moderate, and severe), and diplopia (mild, present on lateral gaze to 1 side; moderate, present on lateral gaze to both sides; severe, present on looking straight ahead) and visual characteristics (papilledema, visual fields, and visual acuity). Patient follow-up ranged from 2 months to 9 years, with a mean of 2 years.

The papilledema was considered mild if there was just blurring of disk margins, moderate if there was definite disk elevation, and severe if there was marked disk elevation.

If there was definite peripheral visual field constriction, the field loss was considered to be mild; if there was moderate peripheral constriction, then the field loss was considered moderate; and if the field was constricted to $\leq 20^{\circ}$, it was considered severe.

Visual acuity was defined as severely impaired if $6 / 36$ or worse, moderately impaired if 6/18-6/24, and mildly impaired if 6/9-6/12.

Previous Medical Treatment. All 52 patients had either trialled and failed medical management (medications such as acetazolamide and weight loss) or had fulminant visual loss (4 patients) before stent placement.

Other Operative Treatments. Before stent placement, 4 patients had undergone emergency bilateral sequential optic nerve sheath fenestration due to rapid visual loss from fulminant IIH. One patient had a ventricular drain, and another, a lumbar drain. Two patients had pre-existing nonfunctioning lumboperitoneal shunts. One patient underwent bilateral subtemporal decompression for ongoing headache with normal pressures 6 months after stent placement.

\section{MR Imaging Technique}

All patients had been studied with standard MR imaging of the brain and cerebral MRV, with ATECO 3D gadolinium-enhanced MRV sequences ${ }^{9}$ used since 2006. Patients who met diagnostic criteria for IIH and had TSS on MRV of either transverse sinus went on to have direct retrograde cerebral venography and manometry.

\section{Venography and Manometry}

Cerebral venography and manometry were performed with the patient under light sedation via right femoral venous puncture with a short $6 \mathrm{~F}$ sheath and a $6 \mathrm{~F}$ guide catheter into the right internal jugular vein below the jugular bulb. Access into the superior sagittal sinus was usually straightforward with a Renegade Hi-Flo microcatheter (Boston Scientific, Natick, Massachusetts) over a microwire. Contrast was injected through the microcatheter with venographic assessment of the superior sagittal sinus and both transverse and sigmoid sinuses. Cerebral venous pressure at various locations was measured by attaching a pressure transducer to the microcatheter and taking a zero reference point at the midaxillary line. The type of stenosis present (intrinsic or extrinsic or both) was assessed by the neuroradiologist doing the venogram and was independently reviewed later by another neuroradiologist.

A transverse sinus stenosis on 1 side with a normal transverse sinus on the other side with normal venous pressures was considered to be a normal variation, and these patients were excluded.

Indications for Stent Placement. In the 9 years of this study, 80 patients with IIH with unremitting symptoms had catheter venograms; transverse sinus stent placement was recommended and performed in only the 52 who had transverse sinus stenosis with a pressure gradient of $>8 \mathrm{~mm} \mathrm{Hg}$. A level of $8 \mathrm{~mm} \mathrm{Hg}$ evolved during the years as an arbitrary cutoff between normal and abnormal. The decision to stent was also based on clinical symptoms, response to other treatments, and the appearance of stenosis and superior sagittal sinus pressure measurements on manometry. Patients who had irregular stenoses suggesting recanalization of a previously thrombosed transverse sinus were excluded.

\section{Stent Placement Techniques and Details}

All stent placement procedures were performed with the patient under general anesthesia because guide-catheter access and dural stretching during stent insertion can be very painful. All patients had dual antiplatelet medication before the procedure, currently aspirin (150 mg daily) and clopidogrel (75 mg daily), for a week before stent placement. We now estimate aspirin and clopidogrel activity on the day of the procedure (VerifyNow P12Y12 assay; Accumetrics, San Diego, California) $)^{28}$ to ensure adequate antiplatelet cover.

During the procedure, sufficient heparin was administered to double the baseline activated clotting time. If both transverse sinuses were narrowed, the dominant sinus was chosen for stent placement. A 6F Shuttle Select sheath (Cook, Bloomington, Indiana) was used to access the ipsilateral transverse sinus.

A self-expanding or balloon-expandable stent was then placed across the stenosis and sized according to the length of the stenosis and the size of the venous sinus. We currently use the Complete SelfExpanding Stents (Medtronic, Minneapolis, Minnesota), with most cases requiring $8 \times 40 \mathrm{~mm}$ (diameter $\times$ length) or $9 \times 40 \mathrm{~mm}$ size stents. Poststent angioplasty has not been required. Following stent placement, all patients were monitored overnight in intensive care before discharge. All patients remain on clopidogrel for at least 3 months and aspirin for at least 1 year.

\section{Results}

\section{Clinical Observations before and after Stent Placement}

Symptoms. Of the 52 patients, 43 had headaches: 19 had transient visual obscurations, 17 had pulsatile tinnitus, and 6 had diplopia (Table 1). After stent placement, 8 still had some 


\begin{tabular}{|c|c|c|c|c|c|c|}
\hline \multirow[b]{2}{*}{ Clinical Parameter } & \multicolumn{3}{|c|}{ Before Stent } & \multicolumn{3}{|c|}{ After Stent } \\
\hline & Mild & Moderate & Severe & Mild & Moderate & Severe \\
\hline Papilledema & $11^{\mathrm{a}}$ & 27 & 7 & $0^{b}$ & 0 & 0 \\
\hline Visual acuity loss & 4 & 4 & 5 & 3 & 1 & 0 \\
\hline Visual field loss & $19^{c}$ & 6 & 5 & 5 & 2 & 0 \\
\hline Headache & 6 & 22 & 15 & 0 & $8^{d}$ & 0 \\
\hline Transient visual obscurations & 3 & 10 & 6 & 0 & 0 & 0 \\
\hline Pulsatile tinnitus & 6 & 9 & 2 & 0 & 0 & 0 \\
\hline Diplopia & 3 & 2 & 1 & 0 & 0 & 0 \\
\hline
\end{tabular}

a One patient with optic atrophy.

${ }^{\mathrm{b}}$ Four patients with optic atrophy.

c Twelve patients with only enlarged blind spots.

d Six patients who were re-stented.
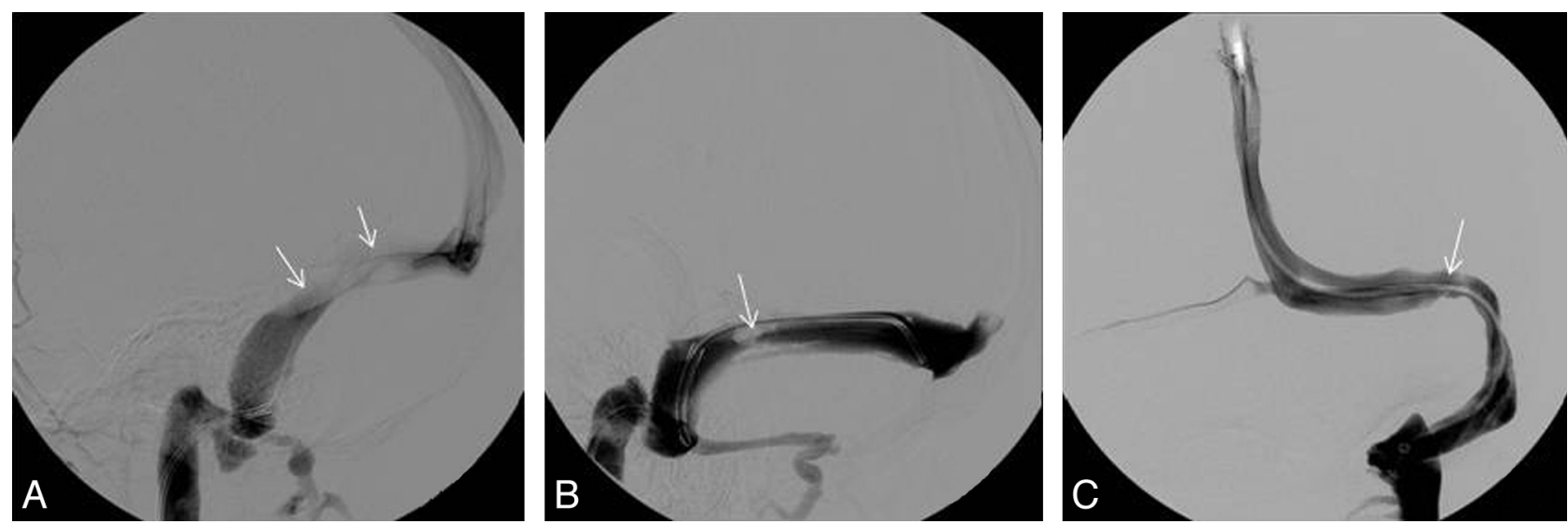

Fig 1. $A$, Example of a stenosis due to extrinsic compression (long narrowed segment, arrow). $B$, Example of an intrinsic stenosis caused by a large arachnoid granulation (arrow). $C$, Example of an intrinsic stenosis caused by a septal band (arrow).

headaches (6 required re-stent placement), which resolved with time in 5 patients. One of these patients required 4 stents but now has normal pressures; another has normal venous pressures, with no gradient after 1 stent; and a third patient had normal pressures after 1 stent but required subtemporal decompression for resolution of headaches. After stent placement, none had visual obscurations, pulsatile tinnitus, or diplopia.

Fulminant IIH. Four patients had acute rapidly progressive bilateral visual loss due to fulminant $\mathrm{IIH}^{29}$

Papilledema. Before stent placement, 46/52 patients had papilledema - all bilateral; 1 patient also had mild optic atrophy. The papilledema was mild in 11 , moderate in 27 , and severe in 7. After stent placement, papilledema resolved in all 46 patients, but 4 patients had secondary optic atrophy (Table 1). In all 6 patients requiring re-stent placement, papilledema resolved after the first stent; while headache recurred in all 6 , papilledema recurred in only 4 . After re-stent placement, the papilledema resolved in all 4 patients, and the headache resolved in 5 of 6 .

Visual Fields. Before stent placement, 30 of the 46 patients with papilledema had significant peripheral visual field loss on quantitative perimetry; 12 had only enlargement of the blind spots. Nineteen patients had mild field loss; 6 patients, moderate; and 5 patients, severe ( 4 fulminant and 1 with optic atrophy). After stent placement, there was persisting peripheral visual field loss in $7 / 46$ patients, mild in 5 , and moderate in 2 (4/7 had optic atrophy).
Table 2: Type of transverse sinus stenosis found at direct venography in 52 patients with IIH

\begin{tabular}{lr}
\hline Type of Stenosis & No. \\
\hline Intrinsic/extrinsic of both sinuses & 16 \\
Intrinsic/extrinsic of dominant sinus, hypoplastic sinus & 8 \\
Intrinsic of both sinuses & 8 \\
Intrinsic of dominant, hypoplastic sinus & 9 \\
Extrinsic of both sinuses & 7 \\
Extrinsic of dominant, hypoplastic sinus & 4 \\
\hline
\end{tabular}

Visual Acuity. Before stent placement, visual acuity was impaired in 13/46 patients with papilledema, severely in 5, moderately in 4 , and only mildly in 4 . Causes of the visual loss were fulminant IIH in 2 patients, macular edema or choroidal folds in 8 patients, optic atrophy in 1 patient, and coexistent cataracts in 2 patients. After stent placement, 4 patients still had visual loss, mild in 3 and moderate in 1 , secondary to optic atrophy in 2 and pre-existing cataracts in 2 patients.

\section{Imaging before and after Stent Placement}

Catheter Venography. All 52 patients had intrinsic or extrinsic transverse sinus stenosis, or both. Intrinsic stenoses were discrete filling defects consistent with large arachnoid granulations or septae. Extrinsic stenoses, sometimes in conjunction with the intrinsic stenosis, were broad smooth regions of tapered narrowing thought to represent external compression as a result of elevated CSF pressure (Fig 1). In all 52 patients, the transverse sinus stenosis was either in the 


\begin{tabular}{|c|c|c|c|c|}
\hline & $\begin{array}{c}\text { Superior Sagittal Sinus } \\
\text { Pressure Pre-stent }(\mathrm{mm} \mathrm{Hg})\end{array}$ & $\begin{array}{c}\text { Superior Sagittal Sinus } \\
\text { Pressure Post-stent }(\mathrm{mm} \mathrm{Hg})\end{array}$ & $\begin{array}{l}\text { Gradient Pre-stent } \\
(\mathrm{mm} \mathrm{Hg})\end{array}$ & $\begin{array}{l}\text { Gradient Post-stent } \\
(\mathrm{mm} \mathrm{Hg})\end{array}$ \\
\hline $\begin{array}{l}\text { With papilledema } \\
(n=46)\end{array}$ & $\begin{array}{c}34 \\
(15-94) \\
(n=46)\end{array}$ & $\begin{array}{c}16 \\
(11-33) \\
(n=44)\end{array}$ & $\begin{array}{c}20 \\
(6-41) \\
(n=46)\end{array}$ & $\begin{array}{c}0.7 \\
(0-14) \\
(n=46)\end{array}$ \\
\hline $\begin{array}{l}\text { Without papilledema } \\
(n=6)\end{array}$ & $\begin{array}{c}25 \\
(18-34) \\
(n=6)\end{array}$ & $\begin{array}{c}11 \\
(7-14) \\
(n=6)\end{array}$ & $\begin{array}{c}12 \\
(4-15) \\
(n=6)\end{array}$ & $\begin{array}{c}0 \\
(n=4)\end{array}$ \\
\hline
\end{tabular}

a Ranges indicated in parentheses.

Table 4: Venous pressures in 40 patients with IIH with papilledema requiring only 1 stent placement procedure versus 6 (all with papilledema at first stent) requiring a second stent placement procedure ${ }^{a}$

\begin{tabular}{|c|c|c|c|c|}
\hline & $\begin{array}{c}\text { Superior Sagittal Sinus } \\
\text { Pre-stent }(\mathrm{mm} \mathrm{Hg})\end{array}$ & $\begin{array}{c}\text { Superior Sagittal Sinus } \\
\text { Post-stent }(\mathrm{mm} \mathrm{Hg})\end{array}$ & $\begin{array}{c}\text { Gradient Pre-stent } \\
(\mathrm{mm} \mathrm{Hg})\end{array}$ & $\begin{array}{c}\text { Gradient Post-stent } \\
(\mathrm{mm} \mathrm{Hg})\end{array}$ \\
\hline $\begin{array}{l}\text { Single stent } \\
\text { ( } n=40 \text {, all with papilledema) }\end{array}$ & $\begin{array}{c}31 \\
(15-94) \\
(n=40)\end{array}$ & $\begin{array}{c}17 \\
(11-33) \\
(n=39)\end{array}$ & $\begin{array}{c}19 \\
(6-36) \\
(n=40)\end{array}$ & $\begin{array}{c}0.4 \\
(0-5) \\
(n=40)\end{array}$ \\
\hline $\begin{array}{l}\text { Repeat stents, on } 1 \text { st stent } \\
\text { ( } n=6 \text {, all with papilledema prior to first stent) }\end{array}$ & $\begin{array}{c}43 \\
(18-56) \\
(n=6)\end{array}$ & $\begin{array}{c}18 \\
(11-32) \\
(n=5)\end{array}$ & $\begin{array}{c}29 \\
(15-41) \\
(n=6)\end{array}$ & $\begin{array}{c}2.8 \\
(0-14) \\
(n=6)\end{array}$ \\
\hline
\end{tabular}

a Ranges indicated in parentheses

dominant transverse sinus (21 patients) or in both transverse sinuses (31 patients) (Table 2). A pressure gradient was found across the stenosis in all 52 patients.

\section{Pressures before and after Stent Placement}

CSF Pressures. Of the 46 patients with papilledema, 37 had lumbar CSF pressure measured before stent placement; the mean pressure was $322 \mathrm{~mm} \mathrm{H}_{2} \mathrm{O}$ (range, 250-730 $\mathrm{mm} \mathrm{H}_{2} \mathrm{O}$ ). After stent placement, lumbar CSF pressure was measured only if there was a clinical indication ( 4 patients), with a mean of $220 \mathrm{~mm} \mathrm{H}_{2} \mathrm{O}$ (range, $130-390 \mathrm{~mm} \mathrm{H}_{2} \mathrm{O}$ ). Only 4 of the 6 patients without papilledema had CSF pressure measured before stent placement, with a mean of $390 \mathrm{~mm} \mathrm{H}_{2} \mathrm{O}$ (range, 300-650 $\mathrm{mm} \mathrm{H}_{2} \mathrm{O}$ ); none had CSF pressure measured after stent placement.

Venous Pressures. Superior sagittal sinus pressure (Table 3) was measured before stent placement in all 46 patients with papilledema, with a mean of $34 \mathrm{~mm} \mathrm{Hg}$ (range, 15-94 mm Hg) (equivalent to $462 \mathrm{~mm} \mathrm{H}_{2} \mathrm{O}$ ). After stent placement, superior sagittal sinus pressure decreased to a mean of $16 \mathrm{~mm} \mathrm{Hg}$ (range, 11-33 mm Hg) (equals $218 \mathrm{~mm} \mathrm{H}_{2} \mathrm{O}$ ). Before stent placement, the mean venous pressure gradient across the main stenosis in the 46 patients with papilledema was $20 \mathrm{~mm} \mathrm{Hg}$ (range, 6-41 mm Hg); immediately after stent placement, it was $<1 \mathrm{~mm} \mathrm{Hg}$ (range, $0-14 \mathrm{~mm} \mathrm{Hg}$ ). In the 6 patients without papilledema, the superior sagittal sinus pressure before stent placement was $25 \mathrm{~mm} \mathrm{Hg}$ (range, 18-34 mm Hg) (equals $340 \mathrm{~mm} \mathrm{H}_{2} \mathrm{O}$ ), and after stent placement, it fell to $12 \mathrm{~mm} \mathrm{Hg}$ (range, 7-14 mm Hg) (equals $163 \mathrm{~mm} \mathrm{H}_{2} \mathrm{O}$ ); the gradient fell from $11 \mathrm{~mm} \mathrm{Hg}$ (range, $4-15 \mathrm{~mm} \mathrm{Hg}$ ) before stent placement to $0 \mathrm{~mm} \mathrm{Hg}$ after stenting.

\section{Stent Placement}

Stent Placement Procedures. Only 1 stent placement procedure was required in 46 patients ( 40 with papilledema, 6 without). Six patients (all with papilledema initially) required repeat stent placement for a new adjacent stenosis in 1 or both transverse sinuses, with recurrence of symptoms: Five patients required 2 stent placement procedures, and the other required 4 stent placement procedures.

Side of Stent Placement. The dominant transverse sinus was stented in all 52 patients, the right in 36 and the left in 16. At the first stent placement procedure, 5/52 patients required $>1$ stent: 4 required 2 stents and 1 required 3 stents. Of these 5 patients, 4 had extrinsic compression, and 1, intrinsic stenosis.

\section{Venography and Manometry before and after Re-Stent Placement}

Even before the first stent, those 6 patients (all with papilledema) who eventually needed re-stent placement had higher pressures than the 40 with papilledema who did not, with a mean lumbar CSF pressure before stent placement of $350 \mathrm{~mm}$ $\mathrm{H}_{2} \mathrm{O}$ versus $312 \mathrm{~mm} \mathrm{H}_{2} \mathrm{O}$ in the 40 who did not need re-stent placement (Table 4). The mean sagittal sinus pressure was 43 $\mathrm{mm} \mathrm{Hg}\left(585 \mathrm{~mm} \mathrm{H}_{2} \mathrm{O}\right)$ in those who needed re-stent placement versus $31 \mathrm{~mm} \mathrm{Hg}\left(421 \mathrm{~mm} \mathrm{H}_{2} \mathrm{O}\right)$ in those who did not. The venous pressure gradient was $29 \mathrm{~mm} \mathrm{Hg}$ in the 6 who needed re-stent placement versus $19 \mathrm{~mm} \mathrm{Hg}$ in the 40 with papilledema who did not.

In the 6 patients who required re-stenting, the mean time to placement of the second stent was 20 months (range, 1-58 months). Four patients had repeat LPs before placement of the second stent, with a mean pressure of $238 \mathrm{~mm} \mathrm{H}_{2} \mathrm{O}(170-310$ $\mathrm{mm} \mathrm{H}_{2} 0$ ). All 6 patients had ongoing elevations of their superior sagittal sinus pressure on venography with a mean of 26 $\mathrm{mm} \mathrm{Hg}(16-41 \mathrm{~mm} \mathrm{Hg})$ and a mean gradient of $19 \mathrm{~mm} \mathrm{Hg}$ (10-34 mm Hg)

In 5 of the 6 patients requiring re-stent placement, follow-up venography had demonstrated transverse sinus narrowing adjacent to the stent, consistent with external compression, as well as a pressure gradient across the stenosis. We have not observed in-stent restenosis occurring in any patient. In 4 of the 5 patients who required 2 stent placement procedures, the second stent was for stenosis due to extrinsic compression on the ipsilateral side. In 1 patient, the contralateral transverse sinus was stented for an intrinsic stenosis. In the 1 
patient who required 4 stents, the first 3 stents were on the ipsilateral side and for ongoing extrinsic compression, whereas the fourth stent was on the contralateral side for an intrinsic stenosis.

In the patient who required 4 stents, the papilledema completely resolved after the second stent, though she continued to have elevated pressures on LP and cerebral venography (sagittal sinus pressure between 27 and $37 \mathrm{~mm} \mathrm{Hg}$ and a pressure gradient between 12 and $18 \mathrm{~mm} \mathrm{Hg}$ ). After 4 stents, the patient still has headaches despite normal pressures on intracranial pressure monitoring through a Rickham reservoir (Codman and Shurtleff, Bridgewater, Massachusetts), suggesting a cause for the headache unrelated to intracranial pressure.

\section{Complications}

After stent placement, patients often experienced ipsilateral frontal headache, which resolved within the first week and was likely secondary to dural stretching by the stent. Two patients had allergic reactions to aspirin or clopidogrel, 2 patients had transient hearing loss, and 1 patient had an anaphylactic reaction to the anesthetic (muscle relaxant) but made a full recovery. Two patients had significant neurologic complications during stent placement. In the first patient, the guidewire perforated a vein causing a subdural hematoma. In the second patient, subdural, subarachnoid, and intracerebral bleeding occurred at the time of emergency treatment for fulminant IIH but on the side contralateral to the stent placement treatment. Both patients underwent immediate craniotomy and made a full recovery.

Care must be taken in the anesthetic management of patients who undergo transverse sinus stent placement, due to the potential effects of anesthetic agents, rises in $\mathrm{pCO}_{2}$, and arterial pressure on intracranial pressure. Changes in $\mathrm{pCO}_{2}$ particularly affect intracranial pressure, and thus end-tidal $\mathrm{pCO}_{2}$ should be monitored ${ }^{30}$ and not allowed to rise during emergence from anesthesia. Arterial pressure should also be monitored and not allowed to drop during anesthesia to ensure that cerebral perfusion pressure is maintained.

\section{Discussion}

Many patients with IIH have venous hypertension and stenosis of either the dominant or both transverse sinuses. ${ }^{1}$ All our 52 patients with IIH had high sagittal sinus pressures and stenosis of either their dominant transverse sinus (21 patients) or both transverse sinuses ( 31 patients). Stent placement to open just 1 transverse sinus immediately normalized venous pressures, abolished papilledema in all patients, and resolved $\mathrm{IIH}$ symptoms in 49/52 patients. This suggests that just 1 normally functioning transverse sinus precludes the development of IIH. One stent placement procedure avoided this development in 46 patients, while 5 patients required 2 stent placement procedures and 1 patient 4 procedures. The follow-up ranged from 2 months to 9 years (mean, 2 years).

Most patients with IIH respond to maximal medical therapy (weight loss, repeated LPs, drugs, and so forth). Indications for surgical treatment such as CSF shunt insertion, optic nerve sheath fenestration, or subtemporal decompression include failure of or noncompliance with medical treatment, with new or worsening visual field deficits, intractable head- ache, or fulminant $\mathrm{IIH}^{31}$ Shunts have complications, ${ }^{32}$ including shunt migration and dislocation, infection, acquired Chiari malformation, and intracerebral hemorrhage. ${ }^{33}$ Up to $64 \%$ of ventriculo- and lumboperitoneal shunts fail within 6 months; re-operation is common for recurrence of papilledema and high CSF pressures. ${ }^{34}$ Such poor results have been tolerated due to a lack of a viable alternative. ${ }^{35}$ Optic nerve sheath fenestration has an up to $40 \%$ complication rate, ${ }^{36}$ including visual loss, motility and pupillary dysfunction, and vascular complications. While transverse sinus stent placement has some risk, 5 of our 52 patients had significant complications and $12 \%$ required a repeat procedure, this rate is less than that of the other surgical options. We suggest that transverse sinus stent placement is a safe and effective alternative to CSF shunt surgery; if a CSF shunt is being considered for a patient with IIH, then as long as there is a transverse sinus stenosis with a gradient, transverse sinus stent placement should be considered as an alternative.

Higgins et $\mathrm{al}^{17}$ were the first to report transverse sinus stent placement for IIH; their patient was an overweight woman, unresponsive to medical treatment, with bilateral transverse sinus stenoses and raised lumbar CSF and cerebral venous sinus pressures. Transverse sinus stent placement removed the pressure gradient across the stenosis and improved symptoms and signs. Since the first report of transverse sinus stent placement for IIH in 2002, ${ }^{17}$ individual case reports and small case series have appeared. ${ }^{18-20}$ Higgins et $\mathrm{al}^{21}$ reported 12 more patients with venous sinus stent placement, of whom 5 became asymptomatic, 2 improved, and 5 remained unchanged. However, 5 of their patients had undergone previous CSF diversion procedures, and 2 had functioning ventriculoperitoneal shunts at the time of the stent-they did not improve. Our group $^{22}$ reported 4 patients with stented $\mathrm{IIH}$; headache improved in all 4 and vision, in 3 . Donnet et $\mathrm{al}^{23}$ reported 10 patients with IIH, stented without complication; 6 were cured and 4 improved. Bussiere et $\mathrm{al}^{24}$ reported 10 patients with IIH stented, with resolution of venous hypertension in all and symptom improvement in most.

While there is now evidence for the clinical benefits of tranverse sinus stent placement in IIH, there is still debate on whether the stenosis is the cause or an effect of the intracranial hypertension. ${ }^{37-39}$ A transverse sinus stenosis is found on MRV in most patients with IIH, with a specificity of $93 \%$ and a sensitivity of $93 \% .{ }^{40}$ The stenosis can be "a smooth, tapered narrowing" due to extrinsic compression or "a discrete intraluminal filling defect" causing intrinsic obstruction ${ }^{40}$ or a combination of both. After severe head trauma, intracranial hypertension has been shown to cause partial collapse of the transverse sinus ${ }^{41}$ and to aggravate intracranial hypertension. ${ }^{42}$ Reducing intracranial pressure in IIH through CSF removal or diversion results in a resolution of the transverse sinus stenosis, suggesting that it is a consequence of transverse sinus compression from intracranial hypertension. ${ }^{12-16,43}$ In IIH, CSF pressure and superior sagittal sinus pressures are coupled: During a CSF infusion test, both CSF and superior sagittal sinus pressures rise and then, with drainage, fall together until central venous pressure is reached, reflecting a functional obstruction of the transverse sinus likely caused by a collapse of the transverse sinus from compression by intracranial hypertension. ${ }^{44}$ 
However transverse sinus stenosis can persist in IIH after normalization of CSF pressure. ${ }^{45}$ The venographic filling defects in the transverse sinus ${ }^{10}$ are trabeculae, septae, or arachnoid granulations, and these can be seen in the transverse and sigmoid sinuses on CT and MRV in patients without IIH. ${ }^{46}$ They can produce symptomatic IIH only when they obstruct a dominant transverse sinus or both transverse sinuses. ${ }^{47}$

Our findings suggest that transverse sinus stenosis can be both a cause and an effect of intracranial hypertension. In a minority, localized intrinsic stenosis is the cause. We have previously reported a case with a brain hernia into an arachnoid granulation, ${ }^{48}$ and this is a potential mechanism whereby increased intracranial pressure can cause an arachnoid granulation to swell and lead to increased venous obstruction.

In most, a collapsible transverse sinus, structurally vulnerable to extrinsic compression from intracranial hypertension, perpetuates the situation. It has been proposed on the basis of mathematic models ${ }^{25}$ that intracranial hypertension compresses the collapsible transverse sinus causing venous outflow obstruction, which results in further venous hypertension, which then decreases CSF absorption and causes further increases in intracranial pressure, which then feeds back causing further external compression of the transverse sinus and further stenosis. ${ }^{25}$

In our 52 patients, regardless of whether the stenosis was extrinsic compression, suggesting a secondary cause of stenosis, or intrinsic, suggesting a primary origin, the absence of even 1 normal low-resistance transverse sinus resulted in venous hypertension and the clinical picture of IIH. Creation of just 1 functioning low-resistance transverse sinus by stent placement, resulted in the resolution of venous hypertension and of the IIH.

The 6 patients who required re-stenting had higher sagittal sinus pressures on initial venography and a higher gradient across the stenosis, and 5 of 6 had extrinsic compression on venography. Patients requiring re-stenting were treated early in our series, and we now believe that patients with long extrinsic stenoses should have longer stents inserted at the time of initial stent placement, and by using this strategy, we have had fewer patients requiring re-stenting. It may be that the whole of the collapsible transverse sinus should be stented, not just the narrowed segment.

Following stent placement, 8 patients had ongoing headache and 6 required repeat stent placement. Headache only persisted in 3 patients, 1 patient after 4 stents and 2 patients after 1 stent, both with resolution of papilledema and normal pressures, suggesting another cause for their headaches. Up to $68 \%$ of patients with IIH have other definable pressure-independent headaches. ${ }^{49}$

A mathematic model of intracranial pressure dynamics provides a quantitative rationale for transverse sinus stent placement in $\mathrm{IIH} .{ }^{25}$ This model consists of 5 intracranial compartments, with associated pressures and volumes and fluid flows between them (see On-Line Appendix for an overview). Unlike previous models of intracranial pressure, this model introduces a Starling-like resistance between the proximal and distal venous sinuses. Flow between these compartments depends not only on the pressure differential but also on the pressure within the CSF/brain compartment. A Starling-like resistor, which describes a sinus collapsible by external pres- sures, has important consequences that earlier models failed to produce. Such a model can exist in 1 of 2 stable states-a normal pressure state and a high pressure state. The normal pressure state is the only stable state in the presence of a noncollapsible (ie, rigid) sinus.

In the presence of a collapsible sinus, various perturbations produce a transition from 1 steady state to the other. Such perturbations include an increase in cerebral blood flow, an infusion of CSF (leading to a transition from the normal to elevated state), withdrawal of CSF, or reduction in rate of CSF production (leading to transition from the elevated to normal state). Treatment with acetazolamide (which reduces CSF production) or a CSF shunt (which provides an alternate drainage pathway for CSF) induces transition from a highpressure to normal-pressure state in the model. Repeated LPs with the removal of CSF might have a similar effect. In a simulation of the high-pressure state, insertion of a stent, modeled by removing the Starling-like resistor, giving a rigid-walled venous sinus, results in transition to the normal pressure state (now the only stable state), with further perturbations no longer leading to a high-pressure state (Fig A3 of the Appendix).

We propose that a Starling-like resistor characteristic of the collapsible transverse sinus is the key element in IIH. Although not the actual cause of IIH, a collapsible transverse sinus allows IIH to develop through various perturbations in hemodynamic or CSF physiology. The positive feedback loop switching the system to the high-pressure state could be stopped on reaching maximum collapse of the sinus by the opening of collateral channels. The clear symptomatic response in stented patients confirms the critical role of transverse sinus stenosis.

The current case review is retrospective; thus, the potential biases may limit generalization. The documented presence of transverse sinus stenosis in IIH and the apparent clinical benefits of transverse sinus stent placement in our study justify a randomized controlled trial of stent placement in the treatment of IIH. Given the potential risks of in-stent restenoses of transverse sinus stents, especially given the relatively young patient population, close clinical follow-up is required. In the follow-up period of the current study ( $\leq 9$ years), there has been no instance of in-stent restenosis.

\section{Conclusions}

$\mathrm{IIH}$ is not always benign; severe irreversible visual loss is possible. If a patient is being considered for optic nerve sheath fenestration or shunt placement, they should have CT venography or ATECO MRV; if there is an indication of transverse sinus stenosis, they should have catheter venography and manometry. If venous hypertension with a stenosis and a pressure gradient is found, stent placement by an interventional neuroradiologist should be considered. The opening of 1 transverse sinus by stent placement "short-circuits" IIH by removing the Starling-like resistor, normalizes venous pressures, gives symptomatic relief, and can save or restore vision.

\section{Acknowledgments}

We thank Drs Jonathan Ell, James Gordon, Christopher Levi, and Dennis Lowe for allowing us to report the patients they referred for transverse sinus stent placement. 
Disclosures: Peter McCluskey: Consultant. Alcon Laboratories, Details: Airfare and honorarium to attend advisory board meeting in 2010 (AUD \$1000). Rodney Allan: Research Support (including provision of equipment or materials): Actelion, Details: principal investigator for the Conscious-3 study of clazosentan for vasospasm. Mark Hanlon: Other Financial Relationships: Actelion Pharmaceuticals Australia Pty Ltd. Details: I am involved as site coordinator in a clinical drug trial run by Actelion Pharmaceuticals Australia on behalf of Actelion Pharmaceuticals Ltd Switzerland, for which my employer receives a contractual fee. I obtain no financial benefit from this contractual relationship. Actelion pays my employer a fee of up to AUD $\$ 13,500$ per completed participant and provides a centrifuge and a printer on loan for study purposes. Actelion retains ownership of the centrifuge and printer. G.M. Halmagyi: Honorary Consultant. GN Otometrics, Details: Consultancy in developing a video system for measuring the vestibulo-ocular reflex.

\section{References}

1. Owler BK, Parker G, Halmagyi GM, et al. Cranial venous outflow obstruction and pseudotumour cerebri syndrome. Adv Tech Stand Neurosurg 2005;30:107-74

2. Friedman DI, Jacobson DM. Idiopathic intracranial hypertension. JNeuroophthalmol 2004;24:138-45

3. Daniels AB, Liu GT, Volpe NJ, et al. Profiles of obesity, weight gain, and quality of life in idiopathic intracranial hypertension (pseudotumor cerebri). Am J Ophthalmol 2007;143:635-41

4. Friedman DI. Medication-induced intracranial hypertension in dermatology. Am J Clin Dermatol 2005;6:29-37

5. De Simone R, Ranieri A. Advancement in idiopathic intracranial hypertension pathogenesis: focus on sinus venous stenosis. Neurol Sci 2010;31:S33-39

6. Janny P, Chazal J. Intracranial pressure and sagittal sinus pathology. J Neurosurg 1981;54:424

7. King JO, Mitchell PJ, Thomson KR, et al. Cerebral venography and manometry in idiopathic intracranial hypertension. Neurology 1995;45:2224-28

8. Ayanzen RH, Bird CR, Keller PJ, et al. Cerebral MR venography: normal anatomy and potential diagnostic pitfalls. AJNR Am J Neuroradiol 2000;21:74-78

9. Farb R, Scott J, Willinsky R, et al. Intracranial venous system: gadoliniumenhanced three-dimensional MR venography with auto-triggered elliptic centric-ordered sequence: initial experience. Radiology 2003;206:203-09

10. Strydom MA, Briers N, Bosman MC, et al. The anatomical basis of venographic filling defects of the transverse sinus. Clin Anat 2010;23:153-59

11. Subramaniam RM, Tress BM, King JO, et al. Transverse sinus septum: a new aetiology of idiopathic intracranial hypertension? Australas Radiol 2004;48:114-16

12. King JO, Mitchell PJ, Thomson KR, et al. Manometry combined with cervical puncture in idiopathic intracranial hypertension. Neurology 2002;58:26-30

13. Higgins JN, Pickard JD. Lateral sinus stenosis in idiopathic intracranial hypertension resolving after CSF diversion. Neurology 2004;62:1907-08

14. Rohr A, Dorner L, Stingele R, et al. Reversibility of venous sinus obstruction in idiopathic intracranial hypertension. AJNR Am J Neuroradiol 2007;28:656-59

15. De Simone R, Marano E, Fiorillo C, et al. Sudden re-opening of collapsed transverse sinuses and longstanding clinical remission after a single lumbar puncture in a case of idiopathic intracranial hypertension: pathogenetic implications. Neurol Sci 2005;25:342-44

16. McGonigal A, Bone I, Teasdale E. Resolution of transverse sinus stenosis in idiopathic intracranial hypertension after L-P shunt. Neurology 2004;62:514-15

17. Higgins JN, Owler BK, Cousins C, et al. Venous sinus stenting for refractory benign intracranial hypertension. Lancet 2002;359:228-30

18. Ogungbo B, Roy D, Gholkar A, et al. Endovascular stenting of the transverse sinus in a patient presenting with benign intracranial hypertension. $\mathrm{BrJ} \mathrm{Neu}$ rosurg 2003;17:565-68

19. Rajpal S, Niemann DB, Turk AS. Transverse venous sinus stent placement as treatment for benign intracranial hypertension in a young male: case report and review of the literature. J Neurosurg 2005;102(3 suppl):342-46

20. Métellus P, Levrier O, Fuentes S, et al. Endovascular treatment of benign intracranial hypertension by stent placement in the transverse sinus: therapeutic and pathophysiological considerations illustrated by a case report [in French]. Neurochirurgie 2005;5:113-20

21. Higgins JN, Cousins C, Owler BK, et al. Idiopathic intracranial hypertension: 12 cases treated by venous sinus stenting. J Neurol Neurosurg Psychiatry 2003;74:1662-66

22. Owler BK, Parker G, Halmagyi GM, et al. Pseudotumour cerebri syndrome: venous sinus obstruction and its treatment with stent placement. J Neurosurg 2003;98:1045-55

23. Donnet A, Metellus P, Levrier O, et al. Endovascular treatment of idiopathic intracranial hypertension: clinical and radiologic outcome of 10 consecutive patients. Neurology 2008;70:641-47

24. Bussiere M, Falero R, Nicolle D, et al. Unilateral transverse sinus stenting of patients with idiopathic intracranial hypertension. AJNR Am J Neuroradiol 2010;31:645-50

25. Stevens SA, Previte M. Idiopathic intracranial hypertension and transverse sinus stenosis: a modelling study. Math Med Biol 2007;24:85-109. Epub 2006 Oct 27

26. Friedman DI, Jacobson DM. Diagnostic criteria for idiopathic intracranial hypertension. Neurology 2002;59:1492-95

27. Marcelis J, Silberstein SD. Idiopathic intracranial hypertension without papilledema. Arch Neurol 1991;48:392-99

28. Malinin A, Pokov A, Spergling M, et al. Monitoring platelet inhibition after clopidogrel with the VerifyNow-P2Y12(R) rapid analyzer: the VERIfy Thrombosis risk ASsessment (VERITAS) study. Thromb Res 2007;119:277-84. Epub 2006 Mar 24

29. Thambisetty M, Lavin PJ, Newman NJ, et al. Fulminant idiopathic intracranial hypertension. Neurology 2007;68:229-32

30. Kim S, McNames J, Goldstein B. Intracranial pressure variation associated with changes in end-tidal CO2. Conf Proc IEEE Eng Med Biol Soc 2006;1:9-12

31. Corbett JJ, Thompson HS. The rational management of idiopathic intracranial hypertension. Arch Neurol 1989;46:1049-51

32. Wang VY, Barbaro NM, Lawton MT, et al. Complications of lumboperitoneal shunts. Neurosurgery 2007;60:1045-48

33. Suri A, Pandey P, Mehta VS. Subarachnoid hemorrhage and intracerebral hematoma following lumboperitoneal shunt for pseudotumour cerebri: a rare complication. Neurol India 2002;50:508-10

34. Rosenberg ML, Corbett JJ, Smith C, et al. Cerebrospinal fluid diversion procedures in pseudotumor cerebri. Neurology 1993;43:1071-72

35. Owler B. CSF shunt failure: an ongoing epidemic? J Neurol Neurosurg Psychiatry 2009;80:1185

36. Brazis PW. Clinical review: the surgical treatment of idiopathic pseudotumour cerebri (idiopathic intracranial hypertension). Cephalgia 2008;28:1361-73

37. Corbett JJ, Digre K. Idiopathic intracranial hypertension: an answer to, "the chicken or the egg?” Neurology 2002;58:5-6

38. Friedman DI. Cerebral venous pressure, intra-abdominal pressure, and dural venous sinus stenting in idiopathic intracranial hypertension. J Neuroophthalmol 2006;26:61-64

39. Silberstein SD. McKinstry RC. The death of idiopathic intracranial hypertension? Neurology 2003;60:1406-07

40. Farb RI, Vanek I, Scott JN, et al. Idiopathic intracranial hypertension: the prevalence and morphology of sinovenous stenosis. Neurology 2003;60: 1418-24

41. Osterholm JL. Reaction of the cerebral venous sinus system to acute intracranial hypertension. J Neurosurg 1970;32:654-59

42. Owler BK, Besser M. Extradural hematoma causing venous sinus obstruction and pseudotumour cerebri syndrome. Childs Nerv Syst 2005;21:262-64

43. Stienen A, Weinzierl M, Ludolph A, et al. Obstruction of cerebral venous sinus secondary to idiopathic intracranial hypertension. Eur J Neurol 2008; 15:1416-18

44. Pickard JD, Czosnyka Z, Czosnyka M, et al. Coupling of sagittal sinus pressure and cerebrospinal fluid pressure in idiopathic intracranial hypertension: a preliminary report. Acta Neurochir Suppl 2008;102:283-85

45. Bono F, Giliberto C, Mastrandrea C, et al. Transverse sinus stenoses persist after normalization of the CSF pressures in IIH. Neurology 2005;65:1090-93

46. Roche J, Warner D. Arachnoid granulations in the transverse and sigmoid sinuses: CT, MR and MR angiographic appearance of a normal anatomic variation. AJNR Am J Neuroradiol 1996;17:677-83

47. Arjona A, Delgado F, Fernandez-Romero E. Intracranial hypertension secondary to giant arachnoid granulations. J Neurol Neurosurg Psychiatry 2003;74:418

48. Kollar C, Johnston I, Parker G, et al. Dural arteriovenous fistula in association with heterotopic brain nodule in the transverse sinus. AJNR Am J Neuroradiol 1998;19:1126-28

49. Friedman DI, Rausch EA. Headache diagnosis in patients with treated idiopathic intracranial hypertension. Neurology 2002;58:1551-53 